\title{
EXPERIMENTAL STUDY ON APPLICATION OF MARBLE WASTE AS Conventional Aggregate For Base Course Materials
}

\author{
Lami Gonfa $^{1 *}$, Emer Tucay Quezon ${ }^{2}$ and Anteneh Geremew ${ }^{3}$ \\ ${ }^{1}$ Department of Civil Engineering, Madda Walabu University, Ethiopia. \\ ${ }^{2}$ Civil \& Construction Engineering and Management Streams, Ambo University, Ethiopia. \\ ${ }^{3}$ Faculty of Civil \& Environmental Engineering, Jimma Institute of Technology, Jimma, Ethiopia. \\ Date received 13/6/2020, Date accepted: 29/8/2020 \\ *Corresponding author's email: lammiigonfaa55@gmail.com \\ DOI: $10.33736 /$ jcest.2620.2020
}

\begin{abstract}
Recently, highway and construction industries utilize a substantial quantity of conventional aggregates. The increasing demands for conventional aggregate cause an increase in the cost of construction, reduction of natural resource, and continuing deterioration of the earth's surface. On the other hand, the waste generated from the marble industries during the process of cutting and polishing was increasing day by day all over the world. In Ethiopia, the use of Marble Waste Aggregate materials in road construction as a base course material was not well-known, and it was simply wasted at every place where the marble production was continuing. Therefore, this paper focused on evaluating the possibility of using marble waste aggregate as conventional aggregate in the base course layer of flexible pavements by experimental method. To achieve the objectives of the research, mechanical stabilization and laboratory tests have been carried out at different percentage replacement of Conventional Aggregate by $(0 \%, 20 \%, 40 \%, 50 \%, 60 \%, 80 \%$, and $100 \%)$ of Marble Waste Aggregate weights. Marble wastes materials are collected from Burayyu city, Alisha marble processing industry. The laboratory test results for MWA indicated SG, ACV, AIV, LAA, Flakiness Index, Elongation Index, Plastic Index, Water Absorption, and CBR of $2.74 \%, 23.63 \%, 26.21 \%, 27.03 \%, 26.48 \%, 13.29 \%$, Non Plastic, $0.50 \%$ and $73.3 \%$, respectively. These test results fulfilled the ERA standard specification for some tests, and it showed marginal quality values to the standard specification for GB2 and GB3 base course materials. CBR and gradation test results shown failure to meet the standard specification. Thus, mechanical stabilization was done to improve the mechanical and physical properties of Marble Waste Aggregate. Blending of 80\%MWA with $20 \%$ CA results in SG, ACV, AIV, LAA, Flakiness Index, Elongation Index, Plastic Index, Water Absorption, and CBR of $2.83 \%, 18.2 \%, 21.52 \%, 22.58 \%, 23.79 \%, 16.29 \%$, Non Plastic, $0.80 \%$, and $82.5 \%$ respectively. At this proportion the gradation also observed to fit with the required ERA standard specification of GB2 and GB3 materials. Therefore, the use of marble waste aggregate up to $80 \%$ by weight is recommended for road base course layer, when it is found near to the construction site and in places where the materials are abundantly available.
\end{abstract}

Copyright (C) 2020 UNIMAS Publisher. This is an open access article distributed under the Creative Commons Attribution-NonCommercial-ShareAlike 4.0 International License which permits unrestricted use, distribution, and reproduction in any medium, provided the original work is properly cited.

Keywords: Base Course Material, Conventional Aggregate, Marble Waste Aggregate, Mechanical Stabilization, Physical and Mechanical properties

\subsection{INTRODUCTION}

The road construction industry is one of the major sectors in the world[1].Due to a sharp population increase, rapid industrialization, and high standards of living, a lot of infrastructure developments are taking place that leads to a considerable rise in the extraction and consumption of natural aggregate, increased cost of construction material, increased dumping of waste material and meaningful environmental impacts[2]. Moreover, the growing trend of generating waste material from demolished structures, a waste by-product from Industry and the lack of landfills have raised governments and authorities concern[3]..Over the last decades, the increasing environmental problems arising from explained issue attracts the world's attention to employing waste products as a viable alternative in engineering applications[4]-[6].

Many countries and international establishments have been working for new regulations on how to minimize and reuse the generated waste. One of the major waste generating industries is the construction and marble processing industry. Nearly $70 \%$ of this precious mineral resource gets wasted in the mining processing and polishing procedures [7]. 
In order to specify the use of waste and recycled materials for unbound pavement layers, it is important to understand what the function of these layers is within the pavement section. Depending on whether the pavement structure is flexible or rigid, the function of the unbound layer is different. For rigid pavements, the function of the unbound layer is to prevent pumping, protect against frost action, provide a construction platform, drainage of water, prevent volume change of the subgrade, and increasing structural capacity. To prevent pumping, a base course must be either free draining or resistant to the effects of water. To increase structural capacity, the base course must be able to resist deformation due to loading. The role of the unbound layer for flexible pavements is different in that the primary function is to increase structural capacity[8]-[10].

The unbound aggregate layers constitute a significant intermediate component that contributes to pavement stability and performance. Performance of unbound aggregate materials crushed stone and gravel or crushed gravel bases in base course layers depends on the properties of the individual aggregate particles and the interaction behavior of groups of particles associated with aggregates in a matrix. The importance of the individual particle properties comes from its influence on the group behavior within the matrix[11].

Globally road construction has become very expensive due to the increased costs of raw materials. Natural aggregate is one of the main components in flexible and rigid pavement construction ( $>95 \%)$. Demand for aggregate is high and will only increase in the future as cities grow and demand in infrastructure increases. As available natural resources become scarce, non - renewable and the cost of extracting good quality of the material is increasing the utilization of recycled material and waste material for road construction purposes has become increasingly common[12], [13].Environmental wastes produced by technological and industrial development are increasing, whereas natural resource and disposal areas for those wastes are decreasing day by day. So recycling and reuse of waste materials have become crucial in terms of protection of environment and economy[14].

In Ethiopia, the demand for cement has been growing since then and in 2008 there were four cement plants with a combined production capacity of about 2.85 million metric tons per year as reported by Ethiopian investment agency[15].Conventional aggregate is expensive; hence, the use of Marble waste aggregate, when it is locally available and close to the highway project it can be used as partial replacement of conventional aggregate.

Use this waste makes good economic sense for project owners and contractors. Putting industrial waste materials such as marble waste aggregate, ceramic waste aggregates to use in construction projects will solve several environmental problems, on one hand avoiding the extraction of large quantities of raw materials from the earth and by reducing the landfill areas that would be occupied by these wastes. Therefore, it is important to see an alternative mineral aggregate material in order to save the environment. Thus, this paper attempts at the application of marble waste as a conventional aggregate for base coarse materials in flexible pavement.

The study was conducted on marble waste collected from the Alisha marble processing industries which is located in Burayyu city, Western part of Ethiopia. The study aims at evaluating the usability of marble waste aggregates generated during the marble processing as conventional aggregates in the base course construction procedure. The use of waste marble aggregates has the potential to reduce road construction budgets as well as encourage environmental protection when it is close to the construction site. Different laboratory tests have been conducted on samples that have been collected from the sample site to study material properties, the effect of MWA on the quality requirement of the mix and find maximum replacement rate of CA with MWA needed to produce material that can be used as alternative base course construction material. This tests include sieve analysis, ACV, TFV, AIV, LAA, CBR, Compaction, SG, and Water absorption tests that was used to investigate the materials in the laboratory. 


\subsection{METHODOLOGY}

In order to succeed the objective, purposive sampling techniques have implemented to collect conventional aggregate and marble waste aggregate for laboratory analysis.

\subsection{Research Design}

Figure 1. Flow chart for the research design to conducted laboratory tests such as the physical and mechanical properties of CA and MWA materials, determining the effect of MWA on quality requirements of base course material and blending MWA with CA to find out possible replacement amount that satisfies requirement of the ERA manual standard specification and in accordance with gradation requirement for base course material.

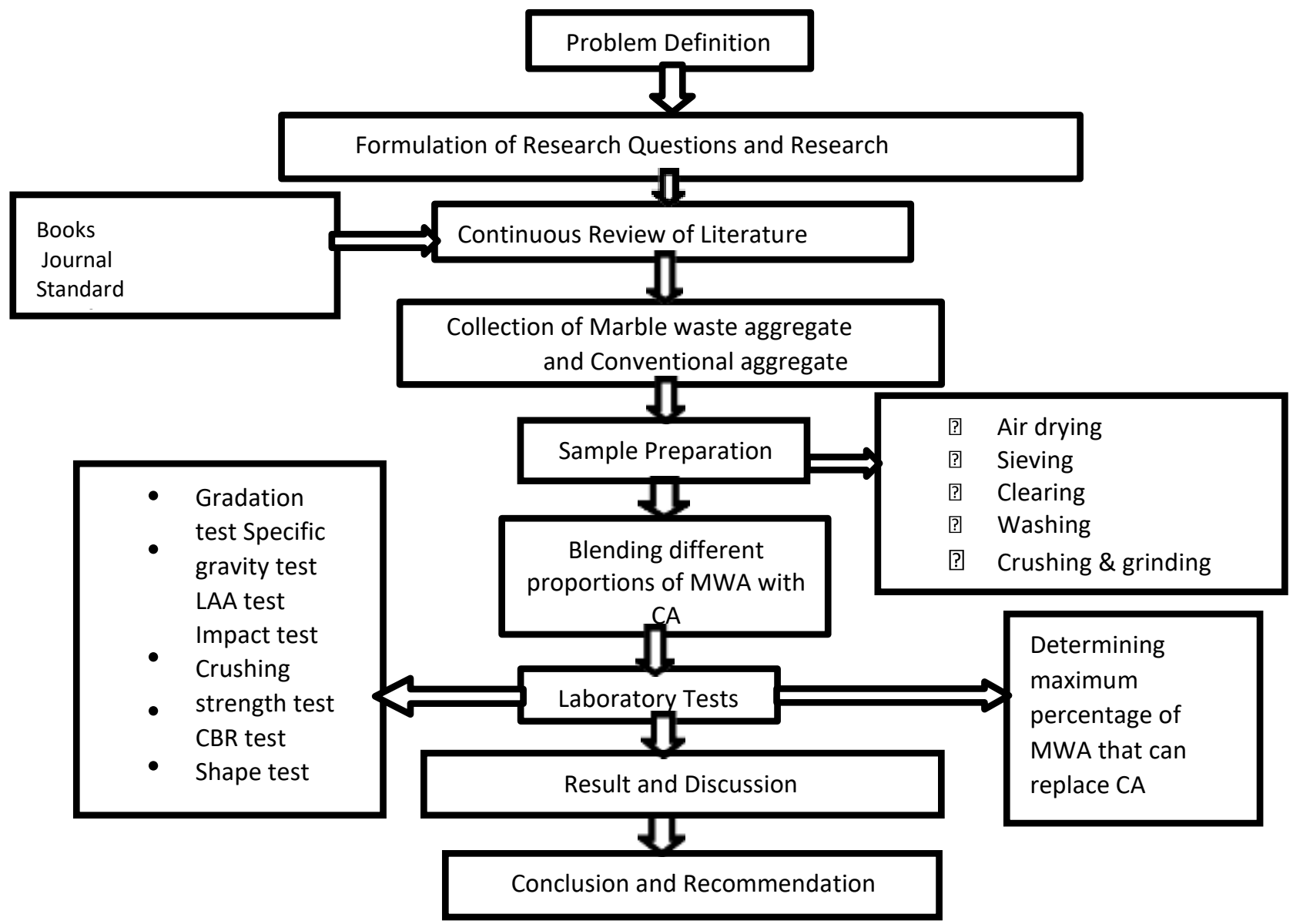

Figure 1. Flow chart for the research design.

\subsection{Sampling Techniques and Procedures}

Sampling techniques, non-probability method, for conventional and marble waste aggregate were used techniques that involves the selection of sample for laboratory analysis. The samples were collected according to the procedure AASHTO T-2 Methodology for sampling from stockpiles and reducing samples of aggregate to testing size was according to AASHTO-T248. For each test, quartering, riffle splitter, and weighting are used for sampling techniques. Sampling activities are shown in Figure 2 and Figure 3. 


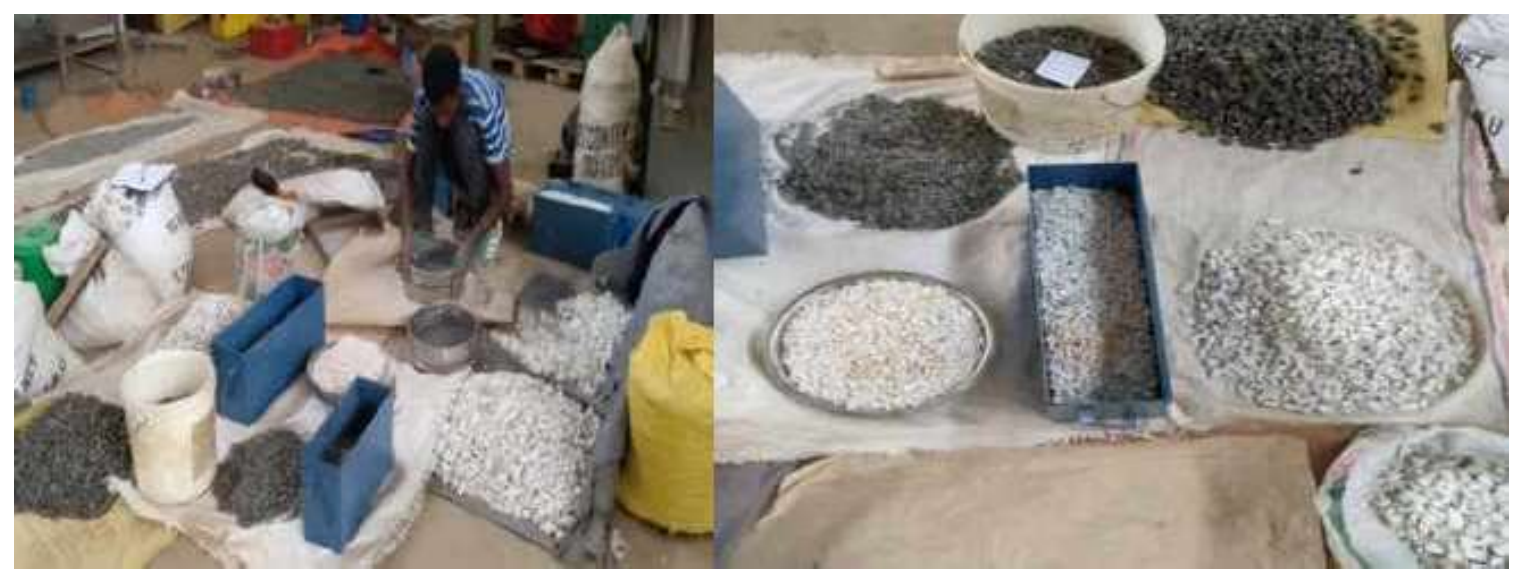

Figure 2. Photos showing Sample preparation of both aggregate types for the test
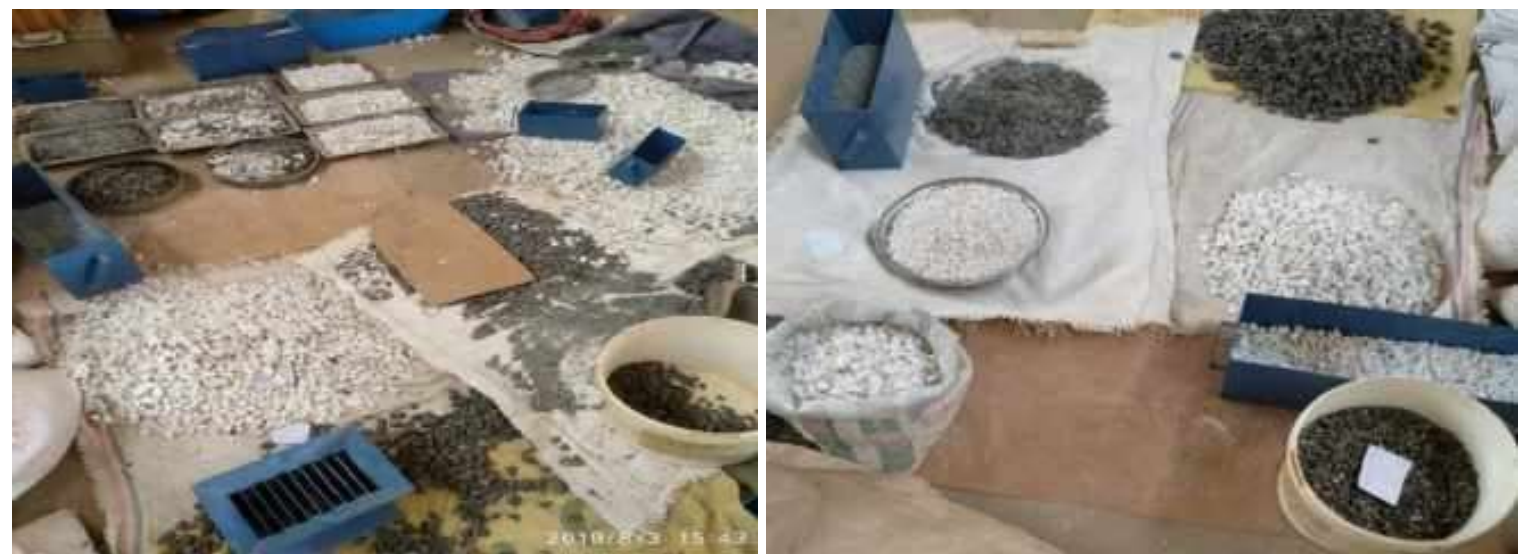

Figure 3. Photos showing sample Quartering done with riffle box splitter

\subsection{RESULT AND DISCUSSION}

\subsection{Physical and Mechanical Properties of Marble Waste Aggregate and Conventional Aggregate}

\subsubsection{Particle Size Distribution MWA and CA}

Based on USCS MWA is coarse-grained aggregate with greater than 50\% retained on \#200 sieve and 5\%$12 \%$ fines (i.e. 8.4\%) with CU value of 68.33 greater than 4 , CC value of 3.15 and having greater than $15 \%$ of sand (i.e. $40.4 \%$ ) it was classified as GW-GM (well-graded gravel with silt and sand). On the same way, CA was coarse- grained aggregate with greater than $50 \%$ retained on \#200 sieve size and less than $5 \%$ fines (i.e. $2.7 \%$ ) with CU value of 23.65 which was much greater than 4 , Cc value of 1.98 that lies between 1 and 3, and having greater than $15 \%$ of sand (i.e. 24.9\%) it was classified as GW (wellgraded gravel with sand). Particle Size Distribution comparisons of Unblended MWA and CA are shown in Figure 4. 


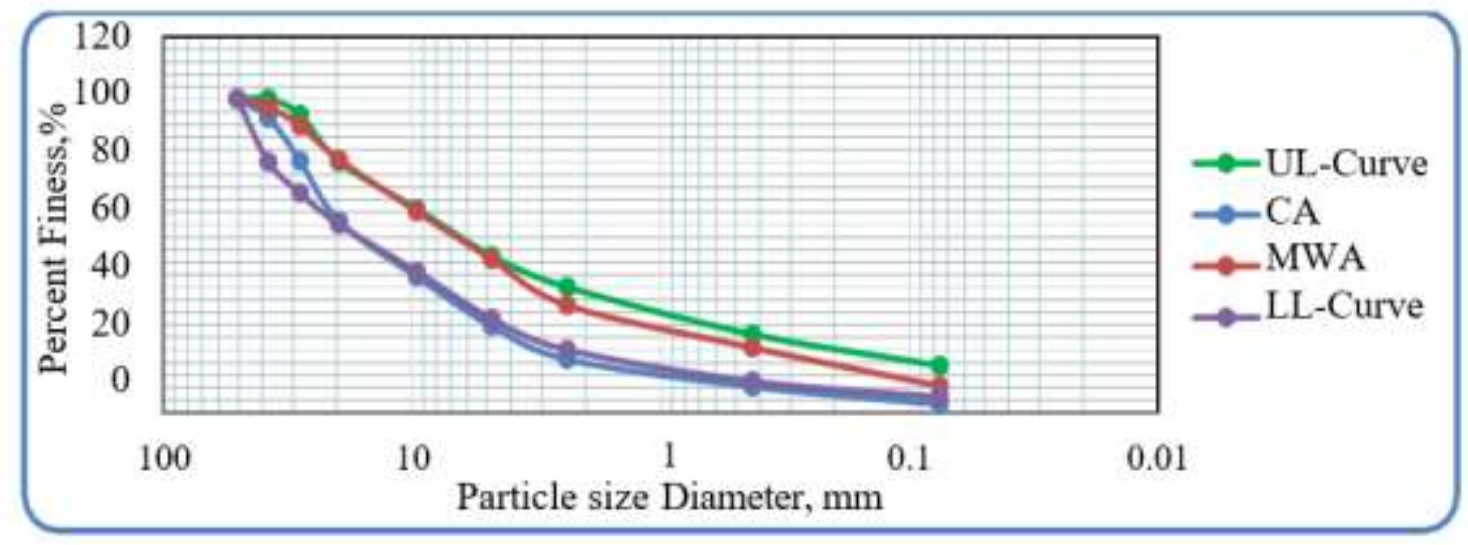

Figure 4. Particle Size Distribution comparisons of Unblended MWA and CA

As per AASHTO soil classification system as shown in Table 1, for granular material if less than $35 \%$ of total samples passing \#200 $(0.075 \mathrm{~mm})$ sieve size and this granular material has also sub-classification A-1, A-3, A-2. Again based on percent of passing sieve sizes of \#10, \#40, \#200 and value of LL and PL the aggregates are reclassified. From the test results of MWA and CA, both materials are classified as A1 -a type of soils having less than $15 \%$ of particles passing sieve opening of size $0.075 \mathrm{~mm}$ and PI of zero. The material contains gravel and sand. Hence, according to AASHTO soil classification system soil classified as A-1-a was preferred for road construction.

Table 1. Aggregate classification by using AASHTO and USCS

\begin{tabular}{|c|c|c|}
\hline \multirow{2}{*}{ Parameters used for Classification } & \multicolumn{2}{|c|}{ Aggregate material type } \\
\cline { 2 - 3 } & MWA & CA \\
\hline D10 $(\mathrm{mm})$ & 0.12 & 0.80 \\
\hline D30 $(\mathrm{mm})$ & 1.76 & 5.47 \\
\hline D60 $(\mathrm{mm})$ & 8.2 & 18.92 \\
\hline Coefficient of Uniformity, CU & 68.33 & 23.65 \\
\hline Coefficient of Curvature, CC & 3.15 & 1.98 \\
\hline Gravel Content, \% & $51.14 \%$ & $72.4 \%$ \\
\hline Sand Content, \% & $40.4 \%$ & $24.9 \%$ \\
\hline Fine Content, \% & $8.4 \%$ & $2.7 \%$ \\
\hline AASHTO Classification & A-1-a & A-1-a \\
\hline USCS Classification & GW-GM & GW \\
\hline
\end{tabular}




\subsubsection{The specific gravity of MWA and CA}

Result for specific gravity and water absorption of MWA and CA are shown in Table 2 and 3 respectively.

Table 2. Result for specific gravity and water absorption of MWA

\begin{tabular}{|c|c|c|c|c|c|}
\hline \multirow[b]{2}{*}{ Particle Size } & \multicolumn{3}{|c|}{ Average Specific Gravity } & \multirow{2}{*}{$\begin{array}{c}\text { Average } \\
\text { Absorption, } \\
\%\end{array}$} & \multirow{2}{*}{$\begin{array}{l}\text { Standard } \\
\text { Specification for } \\
\text { Water absorption }\end{array}$} \\
\hline & $\begin{array}{c}\text { The bulk } \\
\text { (Dry) }\end{array}$ & The bulk (SSD) & Apparent & & \\
\hline Fine MWA & 2.72 & 2.73 & 2.76 & 0.53 & $<2 \%$ \\
\hline Coarse MWA & 2.7 & 2.72 & 2.74 & 0.50 & $<2 \%$ \\
\hline
\end{tabular}

Table 3. Result of specific gravity and water absorption test for CA.

\begin{tabular}{|c|c|c|c|c|c|}
\hline \multirow{2}{*}{ Particle Size } & \multicolumn{3}{|c|}{ Average Specific Gravity } & $\begin{array}{c}\text { Average } \\
\text { Absorption, } \\
\%\end{array}$ & $\begin{array}{c}\text { Standard } \\
\text { Specification for } \\
\text { Water absorption }\end{array}$ \\
\hline Fine MWA & 2.79 & 2.83 & 2.89 & 1.26 & $<2 \%$ \\
\hline Coarse MWA & 2.83 & 2.86 & 2.93 & 1.20 & $<2 \%$ \\
\hline
\end{tabular}

\subsubsection{The Flakiness and Elongation Index for MWA and CA}

The flakiness and elongation index obtained from laboratory tests for MWA are $26.48 \%$ and $13.29 \%$, this result indicates that the MWA sample tested was suitable for use as a base coarse materials because it is within the ERA standard specification limit. ERA and BS standard specification recommends the maximum value of FI as 30\%, and the recommended value for elongation index was $10 \%-35 \%$ as per BS standard. Hence MWA satisfies both requirements of shape test, but the value of the flakiness index was somewhat near to the maximum value, to improve this little blending amount was required. Flakiness and elongation index of CA are $14.44 \%$ and $12.26 \%$ respectively and they are also within the ERA standard specification for Base coarse materials in pavement construction. MWA and CA Flakiness and Elongation test results are shown in Table 4.

Table 4. MWA and CA Flakiness and Elongation test result

\begin{tabular}{|c|c|c|}
\hline \multirow{2}{*}{ Aggregate type } & \multicolumn{2}{|c|}{ Flakiness and Elongation Index Value } \\
\cline { 2 - 3 } & FI, (\%) & EI, (\%) \\
\hline CA & 14.44 & 12.26 \\
\hline MWA & 26.48 & 13.29 \\
\hline
\end{tabular}




\subsubsection{Aggregate Crushing Value (ACV) for MWA and CA}

The Aggregate Crushing Value (ACV) for MWA \& CA test results shown in Table 5 is obviously indicates that the aggregate crushing value for MWA was $23.63 \%$ and $8.91 \%$ for CA. The values obtained from the test results are within the ERA standard specification for base course material.

Table 5. Aggregate Crushing Value (ACV) for MWA \& CA

\begin{tabular}{|c|c|c|c|c|}
\hline & MWA & CA & ERA,2013 Standard specification & Remark \\
\hline $\begin{array}{c}\text { Average ACV } \\
(\%)\end{array}$ & 23.63 & 8.91 & $<29$ & $\begin{array}{c}\text { Both aggregate types are within the } \\
\text { specification limit for the base course. }\end{array}$ \\
\hline
\end{tabular}

It is predictable that conventional aggregate has more resistance than marble waste aggregate for static impact load. Yet the marble waste aggregate shows good property against the static impact load.

\subsubsection{Ten Percent Fines Value (TFV) for MWA and CA}

The strength and durability requirements of conventional aggregate (crushed stone) shall be assessed using the 10\% Fines Aggregate Crushing Test (10\% FACT), in terms of the dry and wet strength, and the wet/dry ratio related to rock type are specified in ERA specification. In this specification the general requirement for most of the rock type is $110 \mathrm{KN}$ As per BS-812-Part-111. Ten Percent Fines Value result for MWA and CA are shown in Table 6 and 7 respectively. This result tells that marble waste aggregate does not fulfill the minimum requirement for a base course materials in dry condition. But, the ratio of wet to dry condition satisfy minimum requirements of ERA standard specification for base course materials. As anticipated from the literature reviewed, MWA has lower TFV than the conventional aggregate.

Table 6. Ten Percent Fines Value result for MWA

\begin{tabular}{|c|c|c|}
\hline & Ten Percent Fines Value (TFV), KN & $\begin{array}{c}\text { ERA 2013, Standard } \\
\text { Specification for base course }\end{array}$ \\
\hline Dry Condition & 95 & $>110$ \\
\hline Wet Condition & 84.5 & - \\
\hline Ratio Wet/Dry, $\%$ & 88.95 & $>75$ \\
\hline
\end{tabular}

Table 7. Ten Percent Fines Value result for CA

\begin{tabular}{|c|c|c|}
\hline & $\begin{array}{c}\text { Ten Percent Fines Value (TFV), } \\
\text { KN }\end{array}$ & $\begin{array}{c}\text { ERA 2013,Standard Specification for } \\
\text { base course }\end{array}$ \\
\hline Dry Condition & 295 & $>110$ \\
\hline Wet Condition & 284 & - \\
\hline Ratio Wet/Dry, \% & 96.27 & $>75$ \\
\hline
\end{tabular}




\subsubsection{Aggregate Impact Value (AIV) Results for MWA and CA}

As it was clearly observed from Table 8, AIV test results show that the MWA sample collected from the site has much big difference in impact load resistance when compared to that of CA, which means the Conventional aggregate has an excellent resistance capacity of $4.61 \%$ while that of MWA has poor impact resistance of $26.21 \%$. But, the test result in both cases shows that the materials have fulfilled the criteria to be used as a base coarse material as per ERA standard specification. The lower aggregate impact value the greater will be the resistance capacity to impact (toughness) sudden load caused by jumping off the steel tired wheels from one particle to another at different levels that causes severe impact on the aggregates.

Table 8. Results of AIV test for MWA and CA samples

\begin{tabular}{|c|c|c|}
\hline Sample Name & Average AIV, (\%) & $\begin{array}{c}\text { ERA 2013 Governing } \\
\text { Specification }\end{array}$ \\
\hline MWA & 26.21 & AIV $<30 \%$ \\
\hline CA & 4.61 & \\
\hline
\end{tabular}

\subsubsection{Los Angles Abrasion Test (LAA) Results for MWA and CA}

As it was clearly seen from Table 9 the test result shows that before blending MWA with CA both samples were within the allowable ERA standard specification for base course materials requirement. This implies that MWA material was resistant against wearing load happen on it and does not crush under load. The specification of ERA sets the maximum value of LAA $45 \%$ for the unbounded base course (GB2 and GB3). Here the result shows that both MWA and CA satisfy the requirement in terms of LAA for base course materials.

Table 9. Los Angeles Abrasion (LAA) result for Marble Waste \& Conventional aggregate.

\begin{tabular}{|c|c|c|}
\hline Aggregate Type & Average LAA, $(\%)$ & ERA2013, Standard Specification \\
\hline MWA & 27.03 & \multirow{2}{*}{ LAA $<45 \%$} \\
\hline CA & 10.92 & \\
\hline
\end{tabular}

\subsubsection{Moisture - Density Relation of MWA and CA}

Table 10 ahows the results of the compaction test for MWA and CA

Table 10. Result of the compaction test for MWA and CA

\begin{tabular}{|c|c|c|}
\hline Aggregate Type & OMC, $(\%)$ & MDD, $\left(\mathrm{gm} / \mathrm{cm}^{3}\right)$ \\
\hline MWA & 1.06 & 2.13 \\
\hline CA & 2.2 & 2.04 \\
\hline 40\%MWA-60\%CA & 1.72 & 2.07 \\
\hline 50\%MWA-50\%CA & 1.31 & 2.16 \\
\hline 60\%MWA-40\%CA & 1.78 & 2.08 \\
\hline 80\%MWA-20\%CA & 1.39 & 2.08 \\
\hline
\end{tabular}


Figure 5 shows the value of $\mathrm{OMC}$ for marble waste aggregate is lower than that of conventional aggregate, this is due to surface smoothness and water resistance capacity of marble materials. But, the density of marble waste aggregate was to some extent greater than that of conventional aggregate and it was due to the gradation of aggregates, as it was generally known gradation adjustment can improve/increase the maximum dry density.
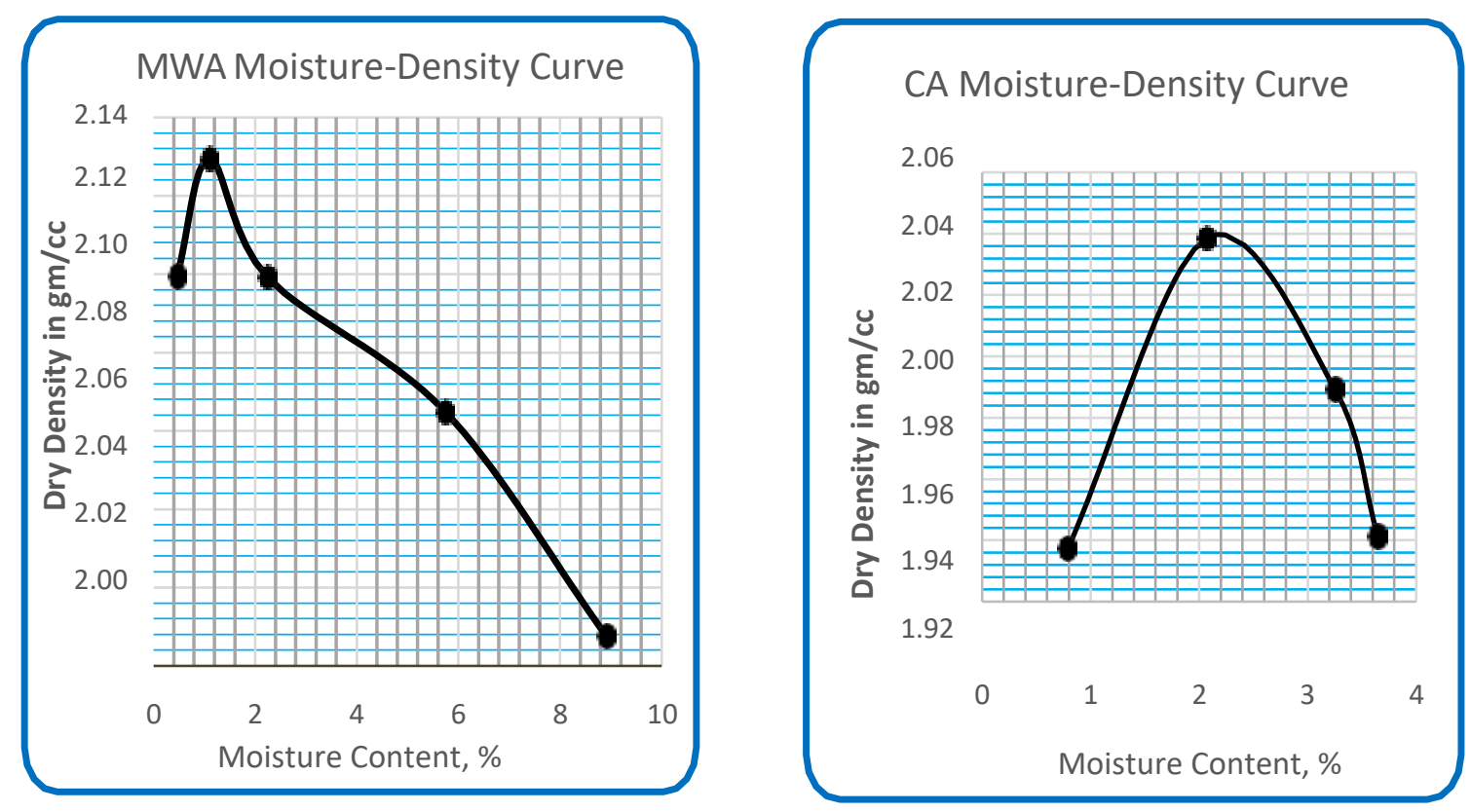

Figure 5. Graph of Moisture-Density Relation of MWA and CA

\subsubsection{CBR Test Results of MWA and CA}

The CBR test result for MWA at 98\%MDD is $73.2 \%$ which was less than the ERA standard specification for (GB2 and GB3) base course materials. Because, ERA recommends minimum CBR value for Mechanically Stable Natural Gravels \& Weathered Rocks for use as Base Course Material (GB2, GB3) was $80 \%$. On the other hand, from the same table, the CBR result for CA at 98\%MDD is $102.9 \%$ which was much higher than the ERA standard specification for base coarse materials (GB1). From both values of CBR values it is obvious that the CBR value of conventional aggregate was greater than marble waste aggregate. Figure 6 and 7 show the results of . Load versus Penetration and Dry density Versus CBR Curve of MWA and CA respectively. 

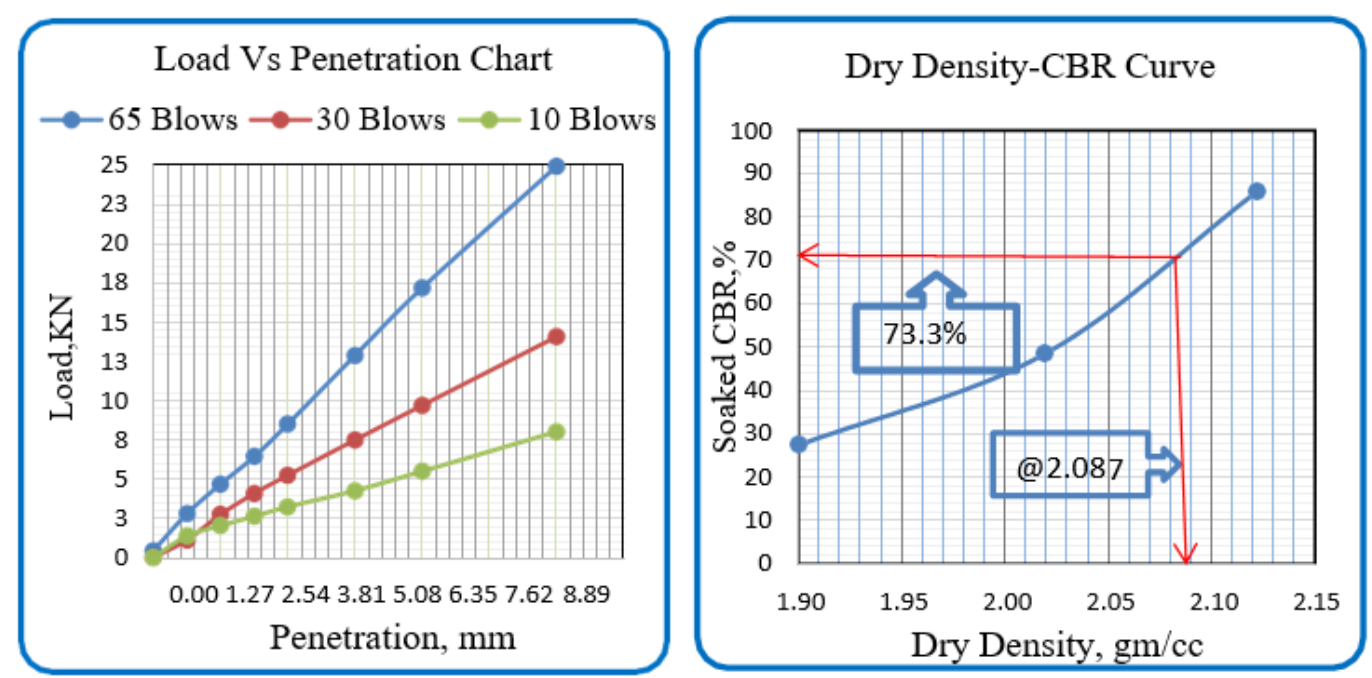

Figure 6. Load versus Penetration and Dry density Versus CBR Curve of MWA
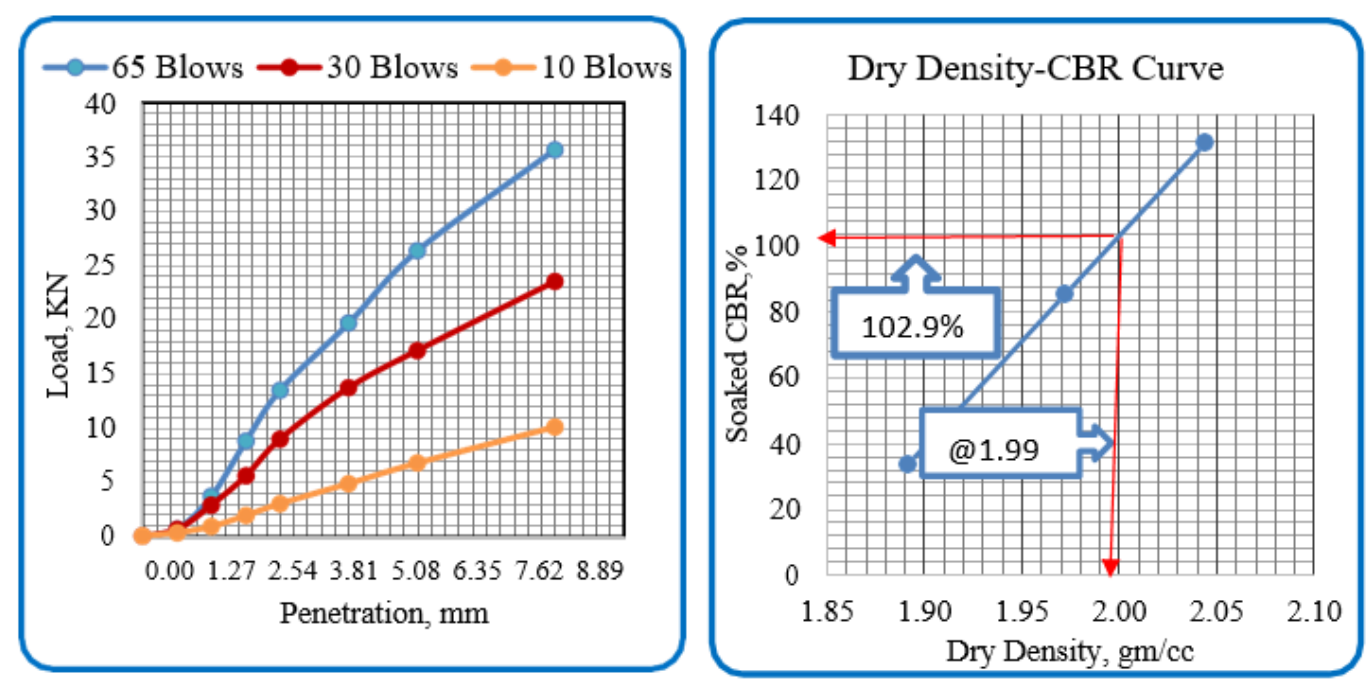

Figure 7. Load vs. Penetration and Dry Density vs. CBR Graph of CA

\subsection{Blending of Aggregates and Determination of the Maximum Percentage of MWA Replacing CA and it's Effect on engineering properties of Aggregates}

Marble waste aggregate sample that was tested to determine its physical and mechanical properties indicates failure to satisfy minimum and maximum limit of ERA standard specification recommended for base coarse materials for Gradation, Ten Percent Fines Value, CBR and shows marginal quality value for the AIV, ACV, FI, and LAA. Hence, the blending of aggregate was required to meet the required of standard specification. Blending was done by trial and error at 20\%MWA-80\%CA,40MWA\%-60\%CA, $50 \%$ MWA-50\%CA, 60\%MWA-40\%CA, and 80\%MWA-20\%CA.

\subsubsection{Particle Size Distribution Blended MWA and CA}

The 80\%MWA mixed with 20\%CA were completely fitted with ERA Standard specification for GB2 and GB3 base course material as shown in Figure 8, which is usually used for a heavy trafficked road in Ethiopia. As it was observed from Figure 9, mix proportion of $80 \%$ MWA-20\%CA has a particle size distribution curve within the acceptable value of ERAfor GB2 and GB3 as a base coarse materials. These mix proportions gradation curve was parallel to the lower and upper limit value and the value of percent passing was close to the target value of the governing specification. 

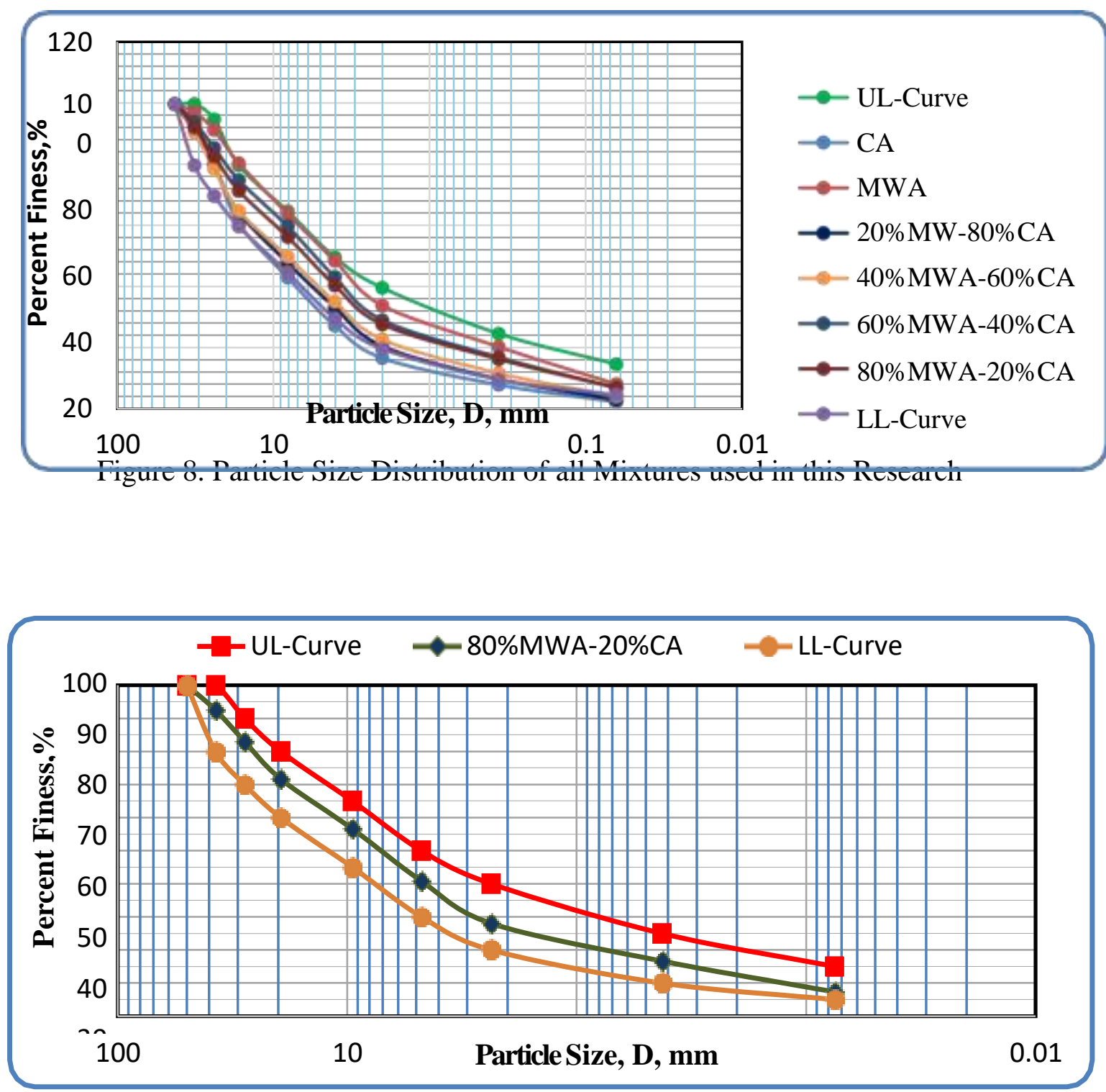

Figure 9. Particle Size Distribution of Blended Aggregates by $80 \%$ MWA-20\%CA

According to ERA standard technical specification, the minimum Grading Modulus shall be two for natural materials used as base course. In Table 11, above the grading modules are calculated for different proportions of MWA and CA. The values of grading modulus in all case is above the minimum required specification. Therefore, the aggregates used are satisfying grading modulus requirements at all mix proportions as base coarse materials. Fineness modulus of coarse aggregate varies from 5.5 to 8.0. And for all in aggregates or combined aggregates fineness modulus varies from 3.5 to 6.5. Fineness modulus of fine aggregate varies from 2.0 to $3.5 \mathrm{~mm}$. Fine aggregate having fineness modulus more than 3.2 should not be considered as fine aggregate[16], [17]. According to this limitation, the aggregate mixes used in this research were not fully coarse or fine, but the combination of the coarse and fine aggregate because FM varies from 3.54 to 4.66 which lies between 3.5 to 6.5 which was FM of all in aggregate or combined aggregates. 
Table 11. Grading and Fineness modulus of aggregate mixes used in this study

\begin{tabular}{|c|c|c|}
\hline Type of mixture & Grading Modulus, (GM) & Fineness modulus, (FM) \\
\hline CA & 2.720 & 4.66 \\
\hline 20\%MWA-80\%CA & 2.654 & 4.46 \\
\hline 40\%MWA-60\%CA & 2.604 & 4.40 \\
\hline 50\%MWA-50\%CA & 2.520 & 4.10 \\
\hline 60\%MWA-40\%CA & 2.460 & 3.87 \\
\hline 80\%MWA-20\%CA & 2.480 & 4.03 \\
\hline MWA & 2.367 & 3.54 \\
\hline
\end{tabular}

\subsubsection{Specific Gravity and Water Absorption Blended MWA and CA}

The limit as per ERA standard specification for maximum absorption for using aggregate material in pavement construction was $2 \%$. Therefore, the results of all tested aggregate much less than the specification value with a maximum of $1.26 \%$ for CA and a minimum of $0.50 \%$ for MWA and the other mixtures have a value between these values as shown on the Table 12.

Specific gravity is the measure of the density of soil or aggregate relative to that of water. Based on this an aggregate with high specific gravity has high density or strength while that of lower specific gravity has low strength. When compared to CA, marble waste aggregate has low specific gravity, this indicates that MWA has low in strength than that of CA. According to ERA 2013, standard specification materials used for base coarse and sub-base construction have a minimum specific gravity of 2.5. Hence, based on the test result shown in Table 12; The MWA has minimum specific gravity of 2.70 and CA has maximum specific gravity of 2.93 and all the other mixture type has specific gravity between this values, in all cases the values obtained from test result was greater than the minimum ERA recommended value, then the aggregates are suitable to use it as a base coarse material based on their specific gravity and water absorption value.

Table 12. Specific gravity of all mixtures used in this Research

\begin{tabular}{|c|c|c|c|c|c|}
\hline \multirow{2}{*}{ Mixture Name } & \multirow{2}{*}{$\begin{array}{l}\text { Particle } \\
\text { Type }\end{array}$} & \multicolumn{3}{|c|}{ Average Specific Gravity } & \multirow{2}{*}{$\begin{array}{l}\text { Average } \\
\text { Absorption, \% }\end{array}$} \\
\hline & & The bulk (Dry) & The bulk (SSD) & Apparent & \\
\hline \multirow{2}{*}{$20 \% \mathrm{MWA}-80 \% \mathrm{CA}$} & Fine & 2.78 & 2.81 & 2.87 & $1.10<2$ \\
\hline & Coarse & 2.83 & 2.87 & 2.93 & $1.25<2$ \\
\hline \multirow{2}{*}{$40 \% \mathrm{MWA}-60 \% \mathrm{CA}$} & Fine & 2.75 & 2.78 & 2.83 & $1.03<2$ \\
\hline & Coarse & 2.79 & 2.82 & 2.88 & $1.12<2$ \\
\hline \multirow{2}{*}{$50 \% \mathrm{MWA}-50 \% \mathrm{CA}$} & Fine & 2.76 & 2.79 & 2.84 & $1.00<2$ \\
\hline & Coarse & 2.78 & 2.81 & 2.86 & $1.02<2$ \\
\hline \multirow{2}{*}{$60 \% \mathrm{MWA}-40 \% \mathrm{CA}$} & Fine & 2.72 & 2.74 & 2.78 & $0.86<2$ \\
\hline & Coarse & 2.78 & 2.80 & 2.84 & $0.81<2$ \\
\hline \multirow{2}{*}{$80 \%$ MWA-20\%CA } & Fine & 2.73 & 2.75 & 2.79 & $0.75<2$ \\
\hline & Coarse & 2.77 & 2.79 & 2.83 & $0.80<2$ \\
\hline
\end{tabular}




\subsubsection{Atterberg's Limit}

The plastic limit and liquid limit of the MWA and CA samples could not be obtained. Hence it can be taken as non- plastic (NP) due to water repellent in nature. Being NP is the desired quality for the base course (GB1) and for hot mix asphalt aggregate according to ERA and MS-2 specifications. Table 13 shown platic index and plastic product for blended materials. Table 13 shows Plastic index and plastic product for blended materials.

Table 13. Plastic index and plastic product for blended materials

\begin{tabular}{|c|c|c|}
\hline Type of mixture & Plastic index & Plasticity product \\
\hline CA & NP & Zero \\
\hline $20 \%$ MWA-80\%CA & NP & Zero \\
\hline $40 \%$ MWA-60\%CA & NP & Zero \\
\hline $50 \%$ MWA-50\%CA & NP & Zero \\
\hline $60 \%$ MWA-40\%CA & NP & Zero \\
\hline $80 \%$ MWA-20\%CA & NP & Zero \\
\hline MWA & NP & Zero \\
\hline
\end{tabular}

\subsubsection{Flakiness and Elongation Index for blended MWA and CA}

As it was clearly observed from Table 14 and Figure 10 the results of shape tests like flakiness index and elongation index for a different blended proportion of MWA and CA were tabulated and analyzed by the graph. From the graph as a percent of MWA increases the flakiness index also increases, but all mixes have value within the specification limits of ERA and BS standard specification that recommends maximum $\mathrm{FI}<30 \%$ and $\mathrm{EI}$ is between $10 \%-35 \%$. But the blended aggregate have flakiness index of $15.79 \%-23.79 \%$ and elongation index of $14.52 \%-16.29 \%$ which was within the required ERA and BS standard specification.

Table 14.

Flakiness and Elongation Index Value of Blended MWA and CA

\begin{tabular}{|c|c|c|}
\hline \multirow{2}{*}{ Aggregate mix type } & \multicolumn{2}{|c|}{ Flakiness and Elongation Index Value } \\
& FI, $(\%)$ & EI, $(\%)$ \\
\cline { 2 - 3 } & 15.79 & 14.53 \\
\hline 20\%MWA-80\%CA & 16.63 & 15.95 \\
\hline 40\%MWA-60\%CA & 18.78 & 14.52 \\
\hline 50\%MWA-50\%CA & 22.32 & 15.74 \\
\hline 60\%MWA-40\%CA & 23.79 & 16.29 \\
\hline 80\%MWA-20\%CA & & \\
\hline
\end{tabular}

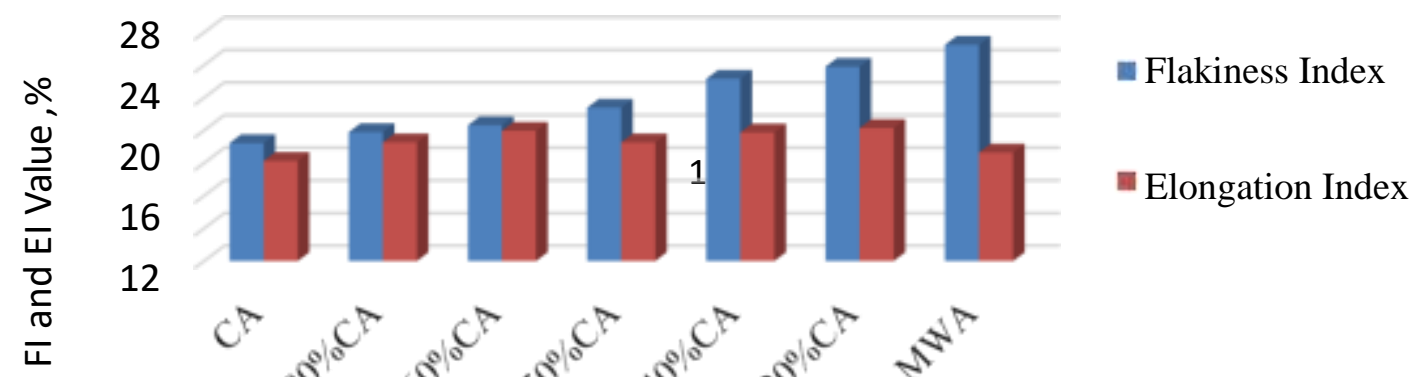


Figure 10. Flakiness and Elongation Index of Different proportion of MWA and CA.

\subsubsection{Aggregate Crushing Value and Ten Percent Fines Value Blended Samples of MWA \& CA}

The laboratory tests are conducted and the results of the test were presented in table 15 . The tests are conducted on the specimens prepared by combining Conventional aggregate with a marble waste aggregate of $20 \%, 40 \%, 50 \%, 60 \%$, and $80 \%$ for a base course material. The aggregate crushing value and ten percent fines value test result clearly shows that replacing CA with all percentages of MWA was not out of ERA standard specification requirement for GB2 and GB3 base course material which requires a maximum value of $29 \% \mathrm{ACV}$ and $110 \mathrm{KN}$ TFV respectively.

Table 15. ACV and TFV Test results for blended MWA and CA

\begin{tabular}{|c|c|c|c|c|c|c|}
\hline \multirow[b]{2}{*}{ Mixtures Name } & \multirow{2}{*}{$\begin{array}{c}\mathrm{ACV} \\
(\%)\end{array}$} & \multicolumn{2}{|c|}{$\mathrm{TFV},(\%)$} & \multirow{2}{*}{$\begin{array}{c}\text { Ratio } \\
\text { Wet/Dry, } \\
(\%)\end{array}$} & \multirow{2}{*}{\multicolumn{2}{|c|}{$\begin{array}{l}\text { ERA 2013, Standard } \\
\text { specification for base } \\
\text { course }\end{array}$}} \\
\hline & & $\begin{array}{c}\text { Dry } \\
\text { Condition }\end{array}$ & $\begin{array}{c}\text { Wet } \\
\text { Condition }\end{array}$ & & & \\
\hline $20 \%$ MWA- $80 \%$ CA & 9.88 & 291.5 & 283.5 & 97.25 & \multirow{5}{*}{$\begin{array}{c}\mathrm{ACV}< \\
29 \%\end{array}$} & \multirow{5}{*}{$\mathrm{TFV}>110 \mathrm{KN}$} \\
\hline $40 \%$ MWA- $60 \%$ CA & 11.10 & 286 & 270 & 94.44 & & \\
\hline $50 \%$ MWA-50\%CA & 13.11 & 265 & 238 & 89.81 & & \\
\hline $60 \%$ MWA-40\%CA & 15.07 & 205.5 & 180.5 & 87.8 & & \\
\hline $80 \%$ MWA- $20 \%$ CA & 18.20 & 154 & 130 & 84.4 & & \\
\hline
\end{tabular}

As it is clearly observed from Table 15 as a percentage of MWA increases the loss due to crushing was increased. But, it is within the standard specification for use as a base course material as per ERA manual. This indicates that MWA has low strength material when compared to CA to stand under gradually crushing force. The samples with higher MWA percentages have poor crushing resistance properties. Since, samples containing higher MWA percentages increased crushing value compared to samples with lower marble waste aggregate percentages, which implies that the base course in MWA was more sensitive to crushing compared to conventional aggregate.

In the same way, TFV also decreases as the percentages of MWA increases. TFV for dry condition decreases from $283.5 \mathrm{KN}$ to $130 \mathrm{KN}$ for $20 \% \mathrm{MWA}$ and $80 \% \mathrm{MWA}$ replacement of CA respectively. The tested MWA material was satisfying principal mechanical properties of base coarse materials and it was satisfactory to resist crushing load under the roller during the construction of roads. Because all mixes were strong enough and within the limit of standard specification to be used for the base course layer of GB2 and GB3 layer according to ERA. 


\subsubsection{Aggregate Impact Value (AIV) for blended MWA and CA}

Table 16 shows that the summary of all test results for different percentage replacement of CA by weight of MWA $(20 \%, 40 \%, 50 \%, 60 \%, 80 \%)$. As is clearly seen from the table AIV were increased $4.61 \%$ of neat CA to $21.52 \%$ at $80 \% \mathrm{MWA}$ replacement. Hence, the higher AIV of the material the lower resisting capacity of the material under sudden impact load

Table 16. Results of AIV test for blended MWA and CA

\begin{tabular}{|c|c|c|}
\hline Mix Name and Proportion & Average AIV, $(\%)$ & $\begin{array}{c}\text { ERA 2013 Governing } \\
\text { Specification }\end{array}$ \\
\hline 20\%MWA-80\%CA & 7.94 & \multirow{2}{*}{ AIV $<30 \%$} \\
\hline 40\%MWA-60\%CA & 12.62 & \\
\hline 50\%MWA-50\%CA & 16.41 & \\
\hline 60\%MWA-40\%CA & 18.49 & \\
\hline 80\%MWA-20\%CA & 21.52 & \\
\hline
\end{tabular}

As shown in Figure 11, aggregate impact value was computed as per BS 812: Part 112:1990 to find out the impact capacity of conventional aggregate and marble waste aggregate. The results of this study were revealed that the data of the minimum impact value significantly increased with the addition of marble waste aggregate. In relation to this ,aggregate impact value ranges from 4.61\%, 7.94\%, 12.62\%, 16.41\%, $18.49 \%, 21.52 \%$, and $26.21 \%$ aggregate after mix with $0 \%$ (conventional aggregate), 20\%MWA, 40\%MWA, 50\%MWA, 60\%MWA, 80\% MWA and 100\%MWA respectively. From the above data, one can safely arrive at the conclusion that the resistance against impact decreases with increasing the percentage of marble waste aggregate in the mixture. In any way, the materials meet the ERA standard specification requirement for base coarse materials which recommend the aggregate impact value of less than $30 \%$.

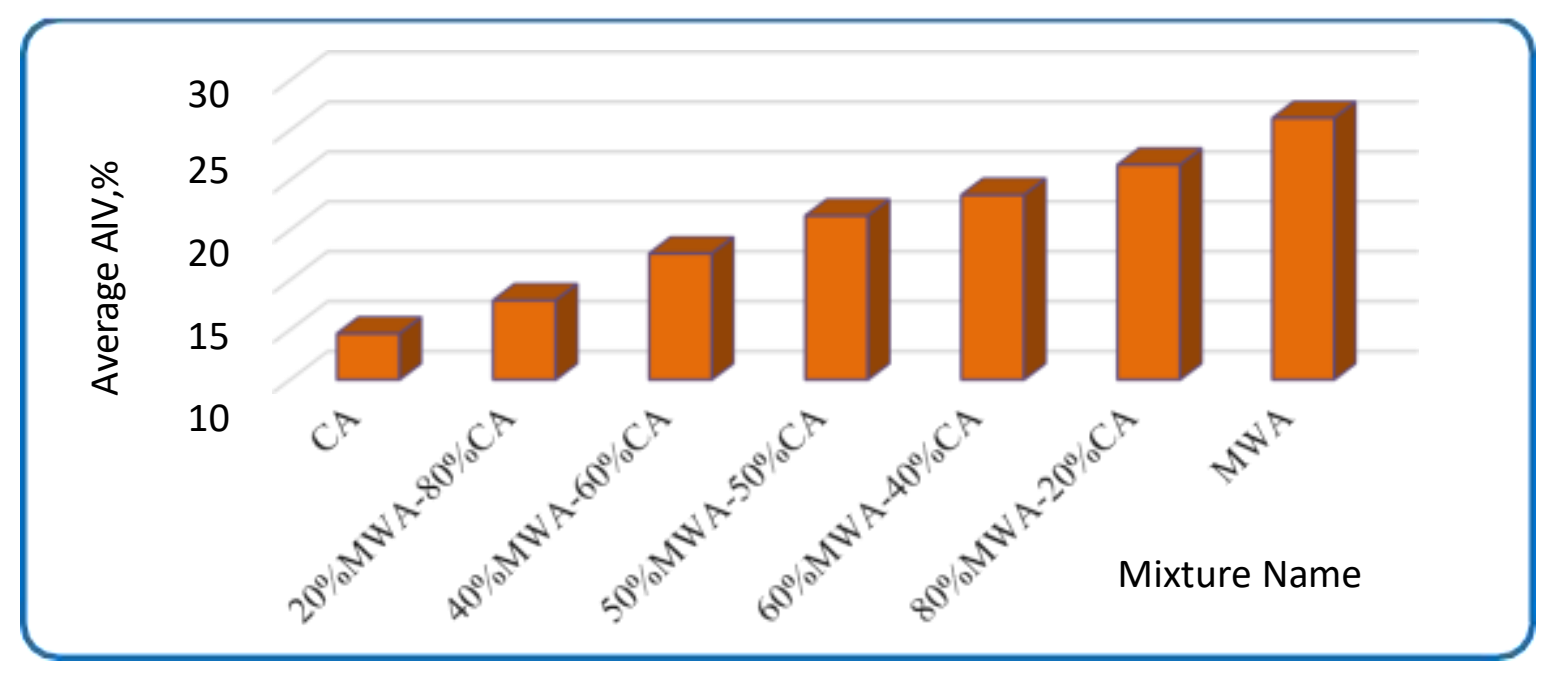

Figure 11. Average AIV of Blended MWA and CA

\subsubsection{Los Angles Abrasion Value (LAAV) for blended MWA and CA}

Table 17 shows LAAV Test Result of Blended Marble Waste and Conventional Aggregate . Requirements of ERA specifications, the maximum abrasion value of the base course is limited to $45 \%$. As can be seen from Figure 12 the mixture containing marble waste aggregate has a lower abrasion value than conventional aggregate, and the resistance against abrasion and impact decreases with the increasing 
percentage of MWA in the mixture. Hence, the result of this test indicates that the use of 100\% MWA in base course construction would not cause any abrasion problems.

Table 17. LAAV Test Result of Blended Marble Waste and Conventional Aggregate

\begin{tabular}{|c|c|c|}
\hline Mix Name and Proportion & Average LAA, (\%) & $\begin{array}{c}\text { ERA 2013 Governing } \\
\text { Specification }\end{array}$ \\
\hline $20 \%$ MWA-80\%CA & 11.26 & \multirow{2}{*}{ LAA<45\% } \\
\hline $40 \%$ MWA-60\%CA & 14.30 & \\
\hline $50 \%$ MWA-50\%CA & 17.84 & \\
\hline $60 \%$ MWA-40\%CA & 21.77 & \\
\hline $80 \%$ MWA-20\%CA & 22.58 & \\
\hline
\end{tabular}

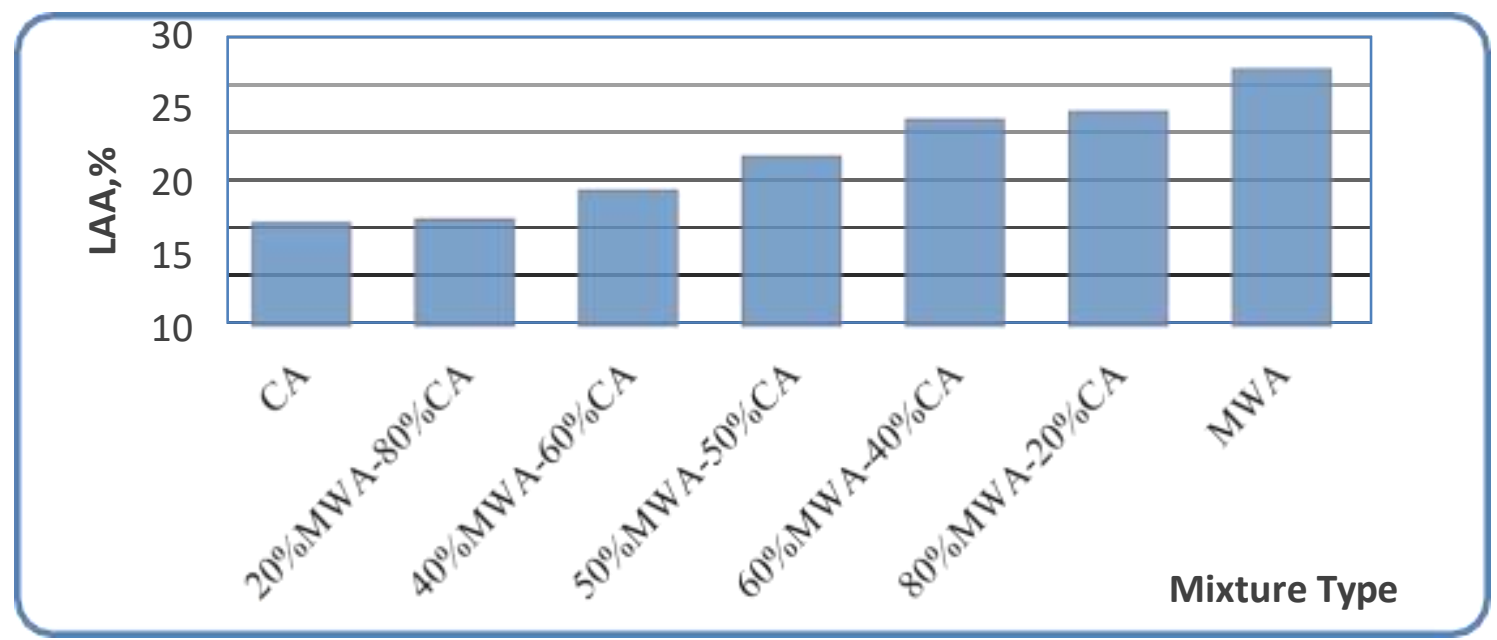

Figure 12. Los Angles Abrasion Test (LAA) Results for blended MWA and CA

\subsubsection{Moisture - Density Relationship of blended MWA and CA}

As it was clearly observed from Figure 13, the optimum moisture content of the mixtures decreases with increasing percentages of marble waste aggregate in the mixtures the values decreases from $2.17 \%$ for $20 \%$ MWA- $80 \%$ CA to $1.39 \%$ for $80 \%$ MWA-20\%CA, that was due to smoothness and water resistance capacity of marble waste. The results of the maximum dry density of the mixture containing marble waste aggregate are slightly higher than that of neat conventional aggregate. Thus, maximum dry density was increased as a percentage of marble waste aggregate was increased slightly in the mixture from $2.05 \mathrm{gm} / \mathrm{cm}^{3}$ to $2.08 \mathrm{gm} / \mathrm{cm}^{3}$ for $20 \%$ MWA- $80 \%$ CA and $80 \%$ MWA-20\%CA respectively. 


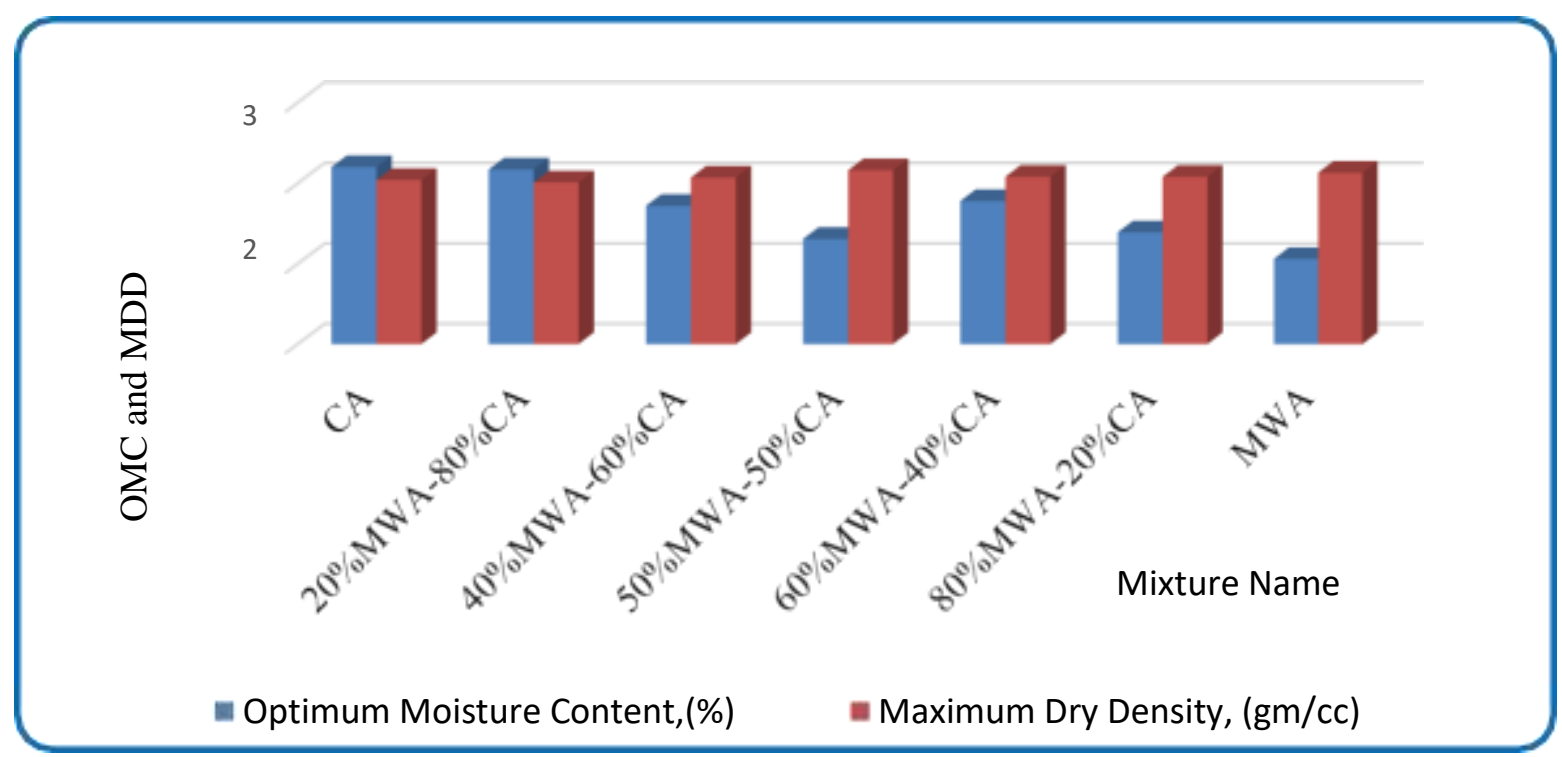

Figure 13. OMC and MDD of marble waste and conventional aggregate mixtures test results.

As it was clearly observed from Figure 14, the optimum moisture content of the mixtures decreases with increasing percentages of marble waste aggregate in the mixtures the values decreases from $2.17 \%$ for $20 \%$ MWA-80\%CA to $1.39 \%$ for $80 \%$ MWA-20\%CA, that was due to smoothness and water resistance capacity of marble waste. The results of the maximum dry density of the mixture containing marble waste aggregate are slightly higher than that of neat conventional aggregate. Thus, maximum dry density was increased as a percentage of marble waste aggregate was increased slightly in the mixture from $2.05 \mathrm{gm} / \mathrm{cm}^{3}$ to $2.08 \mathrm{gm} / \mathrm{cm}^{3}$ for $20 \% \mathrm{MWA}-80 \% \mathrm{CA}$ and $80 \%$ MWA-20\%CA respectively.

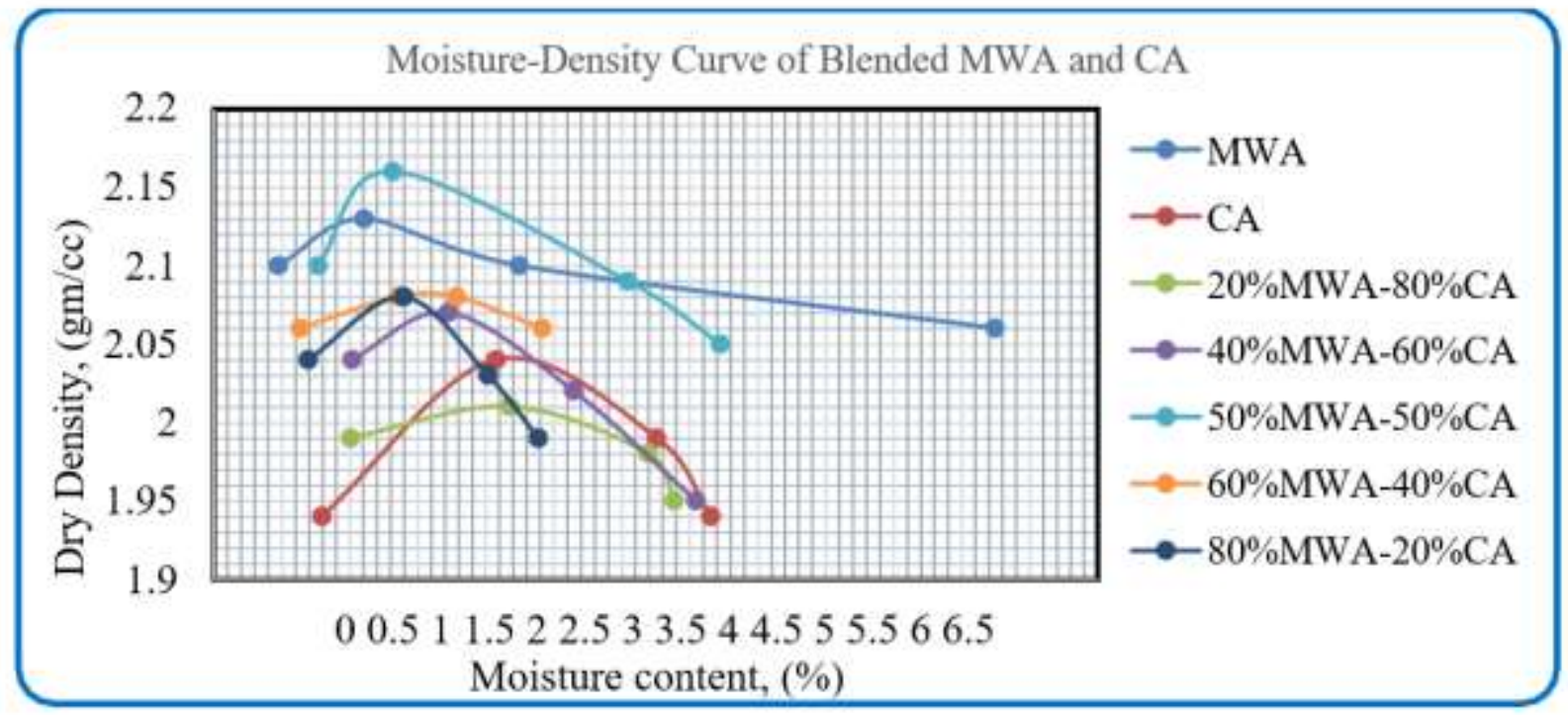

Figure 14. Moisture-Density relation curve of blended MWA and CA

The results also show that the maximum dry density of the mixtures containing marble waste aggregate is slightly higher than those of the mixtures containing conventional aggregate

\subsubsection{California Bearing ratio (CBR) Test Results of Blended MWA and CA}

Table 19 and Figure 15 shows the results CBR test for blended MWA with CA at different proportions to meet the required ERA standard specification of Mechanically Stable Natural Gravels \& Weathered Rocks for use as Base Course Material (GB2, GB3). Then, the values of test results of 20\%MWA- 
80\%CA, 40\%MWA-60\%CA, 50\%MWA-50\%CA, 60\%MWA-40\%CA, and 80\%MWA-20\%CA are $82.5 \%, 86.3 \%, 88.6 \%, 92.7 \%$, and $97.1 \%$ respectively. As it was clearly seen from the values for all condition of blending it satisfies the ERA standard specification recommended which is $>80 \%$ for base coarse material of (GB2 and GB3) and the value of swelling was between 0.00 and 0.01 , this shows that soaking of aggregate material has no much effect on the values of swelling property. Therefore, the marble waste aggregate can be used up to $80 \%$ for unbounded base course (GB2 and GB3) materials as a pavement construction without mentioning strength problems.

Table 19. Results of the CBR test for blended MWA and CA.

\begin{tabular}{|l|c|c|c|}
\hline Aggregate Type & CBR at 98\%MDD, $\%)$ & $\begin{array}{c}\text { Dry Density at } 98 \% \text { of MDD, } \\
\left(\mathrm{gm} / \mathrm{cm}^{3}\right)\end{array}$ & Swell, (\%) \\
\hline $20 \%$ MWA- $80 \% \mathrm{CA}$ & $97.1 \%$ & 1.987 & 0.01 \\
\hline $40 \%$ MWA-60\%CA & $92.7 \%$ & 1.999 & 0.01 \\
\hline $50 \%$ MWA-50\%CA & $88.6 \%$ & 2.117 & 0.01 \\
\hline $60 \%$ MWA-40\%CA & $86.3 \%$ & 2.038 & 0.01 \\
\hline $80 \%$ MWA-20\%CA & $82.5 \%$ & 2.038 & 0.01 \\
\hline
\end{tabular}

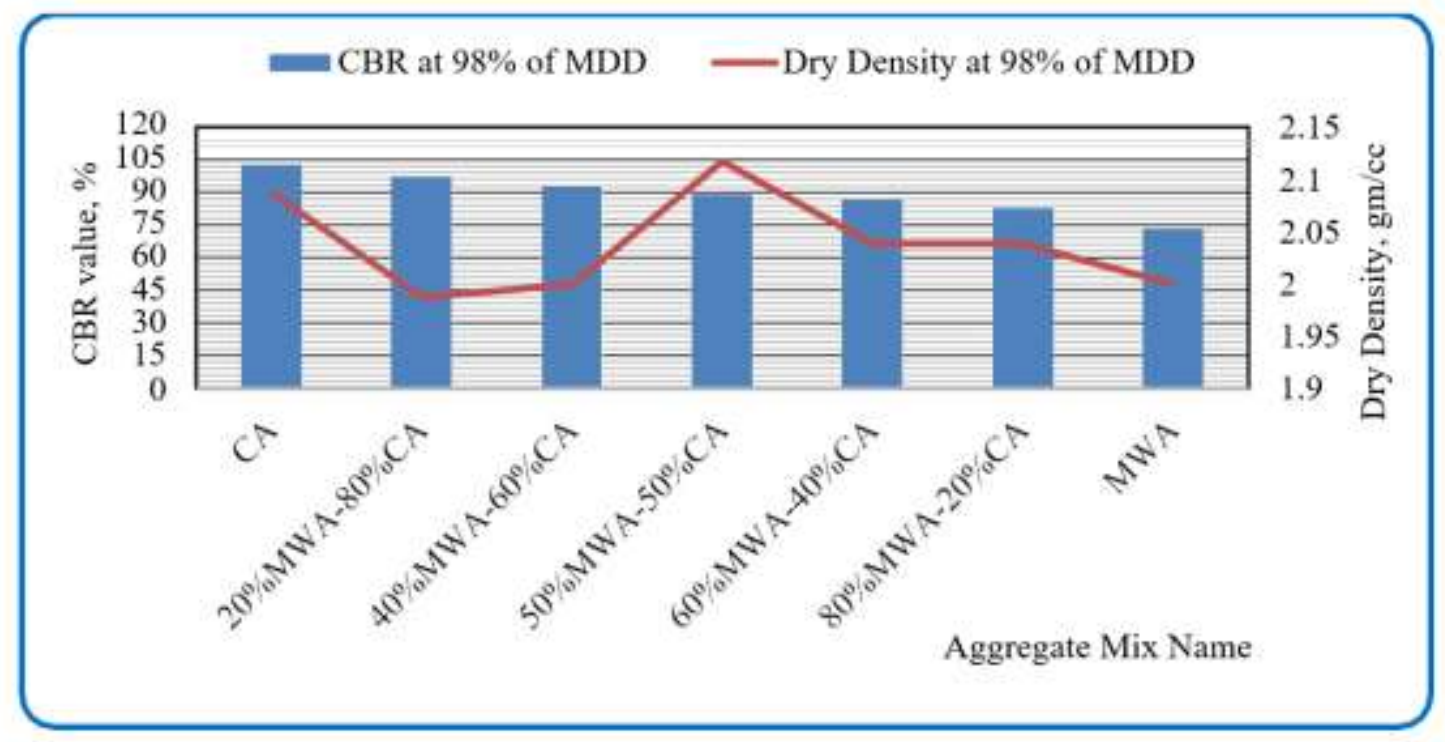

Figure 15. CBR and Dry density at $98 \%$ of MDD of blended MWA and CA.

From all data analysis taken the maximum amount of marble waste aggregate that can replace conventional aggregate was $80 \% \mathrm{MWA} / 20 \% \mathrm{CA}$. Hence, the use of marble waste aggregate up to $80 \%$ (80\%MWA-20\%CA), when it was found near to construction site and in places where MWA was abundantly available might help to meet the increasing demands, reduce demands on existing landfill sites, reduces extraction of conventional aggregates, and slow down any detrimental effects on the environment.

\subsection{CONCLUSION}

- Particle size distribution of MWA and CA does not fulfill the ERA standard specification for MWA (GB2 and GB3) and CA (GB1) of 37.5mm nominal maximum aggregate sizes for base course materials. Hence, the blending of aggregate was required to meet the requirement of standard 
specification. Blending was done by trial and error $80 \%$ MWAmixed with 20\%CA were completely fitted with ERA Standard specification for GB2 and GB3 base course materials.

- Based on the specific gravity test results of MWA and CA, the Specific Gravity and Water absorption of marble waste aggregate was lower than that of conventional aggregate as MWA was light in weight and non-porous material when compared to the conventional aggregate. But, the result of both SG and WA of MWA, CA, and their mixture satisfy the required ERA manual standard specification.

- MWA and CA materials have very low clay content. Therefore, the plastic limit and liquid limit of the MWA and CA samples could not be obtained. Hence it can be taken as non-plastic (NP).

- This study has shown that the test result for ACV, TFV, AIV, and FI of 100\%MWA has marginal quality to be used as base coarse material as per ERA. Blending of MWA with CA at 20\%MWA$80 \%$ CA to $80 \%$ MWA- 20\%CA mix proportion gave ACV of 9.88\%-18.2\% (Max.29\%), TFV of $154 \mathrm{KN}-291.5 \mathrm{KN}(\mathrm{Min} .110 \mathrm{KN}$ ), AIV of 7.94\%-21.52\% (Max. 30\%), LAA value of $11.26 \%-22.58 \%$ ( Max. 45\%), FI value of 15.79\%-23.79 \%( Max.30\%), and EI value 12.26\%-16.29\%( range of specification 10\%-35\%).

- Based on moisture density relationship or compaction test results as percentages of MWA increased in the mixture, the OMC was decreased from $2.17 \%$ to $1.39 \%$, this is due to the smoothness and nonporosity of marble materials, which leads to reduction in amount of water required to achieve MDD, and MDD was increased from $2.05 \mathrm{gm} / \mathrm{cm}^{3}$ to $2.16 \mathrm{gm} / \mathrm{cm}^{3}$.

- The California bearing ratio (CBR) of marble waste aggregate samples do not satisfy the required ERA manual standard specification for base coarse course material in pavement construction. Hence, blending of MWA with CA has done by trial and error, conventional aggregate was replaced at $20 \%$, $40 \%, 50 \%, 60 \%$ and $80 \%$ of MWA by weight, and CBR of the mixes is $97.1 \%, 92.7 \%, 88.6 \%, 86.3 \%$, and $82.5 \%$ respectively. As long as the value of CBR is decreasing as percentages of MWA increased, they are all in all within ERA standard specification for GB2 and GB3 base coarse material that recommends minimum CBR of $80 \%$. Finally, the use of marble waste aggregate up to $80 \%$ (80\%MWA-20\%CA), when it was found near to construction site and in places where MWA was abundantly available might help to meet the increasing demands, reduce demands on existing landfill sites, reduces extraction of conventional aggregates, and slow down any detrimental effects on the environment.

\subsection{ACKNOWLEDGEMENT}

The authors wish to thank the Jimma Institute of Technology, Jimma University in providing the necessary support for carrying out this research study.

\section{REFERENCES}

[1] T. Oladinrin, D. Ogunsemi, and I. Aje, "Role of Construction Sector in Economic Growth: Empirical Evidence from Nigeria," FJOTE, vol. 7, no. 1, pp. 50-60, Oct. 2012, doi: 10.4314/fje.v7i1.4.

[2] H. Schandl et al., "Global Material Flows and Resource Productivity: Forty Years of Evidence: Global Material Flows and Resource Productivity," Journal of Industrial Ecology, vol. 22, no. 4, pp. 827-838, Aug. 2018, doi: 10.1111/jiec.12626.

[3] H. I. Abdel-Shafy and M. S. M. Mansour, "Solid waste issue: Sources, composition, disposal, recycling, and valorization," Egyptian Journal of Petroleum, vol. 27, no. 4, pp. 1275-1290, Dec. 2018, doi: 10.1016/j.ejpe.2018.07.003.

[4] P. O. Akadiri, E. A. Chinyio, and P. O. Olomolaiye, "Design of A Sustainable Building: A Conceptual Framework for Implementing Sustainability in the Building Sector," Buildings, vol. 2, no. 2, pp. 126-152, May 2012, doi: 10.3390/buildings2020126.

[5] N. Ferronato and V. Torretta, "Waste Mismanagement in Developing Countries: A Review of Global Issues," IJERPH, vol. 16, no. 6, p. 1060, Mar. 2019, doi: 10.3390/ijerph16061060.

[6] P. A. Owusu and S. Asumadu-Sarkodie, "A review of renewable energy sources, sustainability issues and climate change mitigation," Cogent Engineering, vol. 3, no. 1, Apr. 2016, doi: 10.1080/23311916.2016.1167990.

[7] H. Akbulut and C. Gürer, "Use of aggregates produced from marble quarry waste in asphalt pavements," Building and Environment, vol. 42, no. 5, pp. 1921-1930, May 2007, doi: 10.1016/j.buildenv.2006.03.012. 
[8] V. R. Schaefer, D. J. White, H. Ceylan, and L. J. Stevens, "Design Guide for Improved Quality of Roadway Subgrades and Subbases," p. 134.

[9] Z. A. Z. Mahdi, "Evaluation of Using the Crushed Concrete Aggregate as Unbound Pavement Layer," Engineering Sciences, p. 7, 2017.

[10] R. J. Salter, "Pavement Construction," in Highway Design and Construction, London: Macmillan Education UK, 1988, pp. 193-219.

[11] H. H. Titi, M. Dakwar, M. Sooman, and H. Tabatabai, "Long term performance of gravel base course layers in asphalt pavements," Case Studies in Construction Materials, vol. 9, p. e00208, Dec. 2018, doi: 10.1016/j.cscm.2018.e00208.

[12] F. Tahmoorian and B. Samali, "Laboratory investigations on the utilization of RCA in asphalt mixtures," International Journal of Pavement Research and Technology, vol. 11, no. 6, pp. 627-638, Nov. 2018, doi: 10.1016/j.ijprt.2018.05.002.

[13] F. Tahmoorian, B. Samali, and J. Yeaman, "Laboratory Investigations on the Utilization of Recycled Construction Aggregates in Asphalt Mixtures," International Journal of Civil and Environmental Engineering, vol. 11, no. 8, p. 7, 2017.

[14] M. Pasetto, M. N. Partl, and G. Tebaldi, Eds., Proceedings of the 5th International Symposium on Asphalt Pavements \& Environment (APE), vol. 48. Cham: Springer International Publishing, 2020.

[15] Abebe Demissew Gashahun, "Assessment on Cement Production Practice and Potential Cement Replacing Materials in Ethiopia," CER, vol. 12, no. 1, pp. 22-28, Jan. 2020.

[16] R. H. Jones and A. R. Dawson, Eds., Unbound aggregates in roads. London ; Boston: Butterworths, 1989.

[17] E. Tutumluer, National Cooperative Highway Research Program, Transportation Research Board, and National Academies of Sciences, Engineering, and Medicine, Practices for Unbound Aggregate Pavement Layers. Washington, D.C.: Transportation Research Board, 2013, p. 22469. 